\title{
EANM Springer Prizes awarded at EANM'13 Lyon
}

\section{MOST CITED PAPER 2012}

FDG-PET changes in brain glucose metabolism from normal cognition to pathologically verified Alzheimer's disease

Lisa Mosconi, Rachel Mistur, Remigiusz Switalski, Wai Hon Tsui, Lidia Glodzik, Yi Li, Elizabeth Pirraglia, Susan De Santi, Barry Reisberg, Thomas Wisniewski, Mony J. de Leon

Eur J Nucl Med Mol Imaging (2009) 36(5):811-822

DOI 10.1007/s00259-008-1039-z

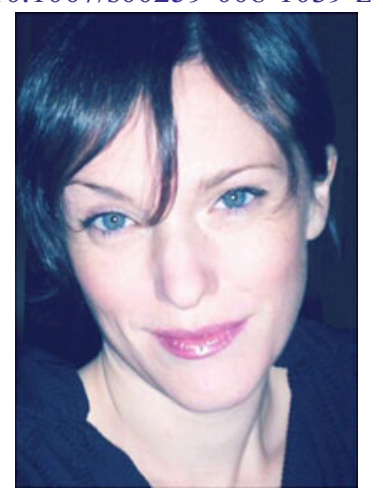

BEST CLINICAL PAPER 2012

$\left[{ }^{11} \mathrm{C}\right]$ Choline PET/CT detection of bone metastases in patients with PSA progression after primary treatment for prostate cancer: comparison with bone scintigraphy

Maria Picchio, Elena Giulia Spinapolice, Federico Fallanca, Cinzia Crivellaro, Giampiero Giovacchini, Luigi Gianolli, Cristina Messa

Eur J Nucl Med Mol Imaging (2012) 39(1):13-26

DOI 10.1007/s00259-011-1920-z

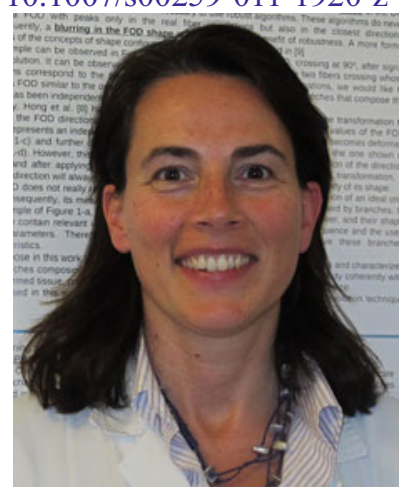

BEST BASIC SCIENCE PAPER 2012

Positron emission tomography imaging of CD105 expression with Zr-89-Df-TRC105

Hao Hong, Gregory W. Severin, Yunan Yang, Jonathan W. Engle, Yin Zhang, Todd E. Barnhart, Glenn Liu, Bryan R. Leigh, Robert J. Nickles, Weibo Cai

Eur J Nucl Med Mol Imaging (2012) 39(1):138-148

DOI 10.1007/s00259-011-1930-x

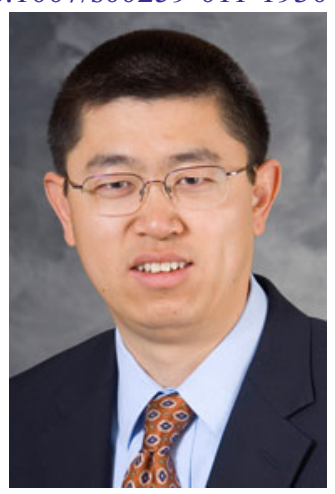

"Society communications"

are items of general interest for the nuclear medicine community:

- Reports on meetings

- National society news

- Courses, fellowships

- Other items of interest

Announcements of meetings or industry advertisements cannot be published in this section.

Mail your text to

societynews@eanm.org

icarrio@santpau.cat 